\title{
CARBON CAPTURE USING AQUEOUS SUSPENSION OF AMINATED POLYACRYLATE PARTICLES
}

\author{
[Cyril Sunday UME*1, Erdoğan ALPER ${ }^{2}$, Adachukwu N. NKWOR ${ }^{3}$ ]
}

\begin{abstract}
Efficient and viable carbon capture technology is a panacea to sustainable use of fossil fuel with less discharge of carbon dioxide to the environment. This research work investigates the kinetics of reaction between carbon dioxide $\left(\mathrm{CO}_{2}\right)$ and aqueous suspension solutions of mono-dispersed polyacrylate particles containing amine group using stopped flow technique.

Two types of suspensions of mono dispersed aminated polyglycidylmethacrylate particles, poly(GMA) were synthesized: non-porous mono dispersed aminated particles, (NPGMA) and porous mono dispersed aminated particles, (PGMA). The dispersion polymerization process was applied to experimentally synthesize the polymer particles, poly(GMA) of average size $2 \mu \mathrm{m}$ in a glass sealed cylindrical reactor. The epoxy group on the micro surface was reacted with ammonia and become covalently attached to the primary amine group on the micro surface. The particles in colloidal suspensions were respectively reacted with $\mathrm{CO}_{2}$ in aqueous solution at $298 \mathrm{~K}$ and its kinetics were monitored and analyzed with stopped flow equipment. It was found that porous mono dispersed aminated poly(GMA), PGMA has a more favourable kinetic properties than the non-porous type. The observed reaction rate constant, $k_{0}$ of the former was found to be $18.37825 \mathrm{~s}^{-1}$ for $0.0270 \mathrm{~g} / \mathrm{ml}$ at $298 \mathrm{~K}$. Based on this study, it can be inferred that PGMA could be applied for $\mathrm{CO}_{2}$ capture. The PGMA is less corrosive, less energy intensive and therefore economical viable because unlike aqueous amine solution system, the slurry after absorbing $\mathrm{CO}_{2}$ can be filtered to remove the water content and only the PGMA beads containing the captured $\mathrm{CO}_{2}$ can be regenerated and recycled.
\end{abstract}

Keywords - $\mathrm{CO}_{2}$ capture, reaction kinetics, poly(GMA), stopped flow technique.

\section{Introduction}

Carbon dioxide, $\left(\mathrm{CO}_{2}\right)$ capture from flue gas stream of process industries is part of environmental issue of major concern in the world today. $\mathrm{CO}_{2}$ is the most important green house gas (GHG) released in abundant quantity to the atmosphere which contributes to global warming. The main objective of this research

Cyril Sunday UME* ${ }^{1}$

Chemistry Department Federal University, Ndufu Alike Ikwo, Ebonyi State,

Nigeria

Erdoğan ALPER ${ }^{2}$

Chemical Engineering Department, Hacettepe University, Ankara - Turkey.

\section{Adachukwu N. NKWOR}

Pure and Industrial Chemistry Department, University of Nigeria, Nsukka - Nigeria.

has been to evolve optimal system for $\mathrm{CO}_{2}$ capture from major point sources as efficient and economical capture system cannot be overemphasized as the leading step to issue of carbon sequestration.

The issue of global warming has resulted in the environmental concern over a reduction of GHGs emission from industrial sources. Among GHGs, $\mathrm{CO}_{2}$ is the primary contributor to the problem due to its high abundance, and thus a major target for reduction. The principal technology to capture $\mathrm{CO}_{2}$ on large scale is the absorption - desorption process, which aqueous solutions of alkanolamines are frequently used as solvents (Kohl and Nielsen, 1997). This process though established and has been operational since 1930, it is energy intensive and costly with other side effects hence the need for alternative and affordable solvent or technology for $\mathrm{CO}_{2}$ capture. In view of the above facts, the challenge of carbon dioxide capture and its sequestration to achieve clean air environment and mitigation of global warming can be enhanced if there is a viable $\mathrm{CO}_{2}$ capture technology from industrial exhaust gases prior to its discharge to the environment as an alternative to amine technology in use.

From the Industrial Revolution era till date, the amount of pollutants emitted into the air has been geometrically increasing due to the availability and use of fossil fuels. According to Weart, 2003; since 1961, Guy Stewart Callendar has confirmed that there is a progressive annual increase in concentration of carbon dioxide in the earth's atmosphere. Notwithstanding that $\mathrm{CO}_{2}$ has the least impact of all the GHGs such as methane $\left(\mathrm{CH}_{4}\right)$, nitrous oxide $\left(\mathrm{N}_{2} \mathrm{O}\right.$ ), hydrofluorocarbons (HFCs), perfluorocarbons (PFCs), chlorofluorocarbons (CFCs) and sulphur hexafluoride $\left(\mathrm{SF}_{6}\right), \mathrm{CO}_{2}$ is considered the most influential GHG because of its large emission volume $\left(6.0 \times 10^{9}-8.2 \mathrm{x}\right.$ $10^{9}$ tonnes $\mathrm{CO}_{2} /$ year on a dry air basis) into the atmosphere (Henni, 2002). Global $\mathrm{CO}_{2}$ emissions have increased by over $70 \%$ between 1971 till date and the earth's average temperature could rise from 1.4 to $6^{\circ} \mathrm{C}$ as carbon emission reaches approximately 26Gt/year by 2100 (Kadiwala, 2008).

In view of these aforementioned statistics, many scientists, industralists and policy-makers observed that the efficient removal and subsequent sequestration of $\mathrm{CO}_{2}$ from postcombustion emission streams is a major lead of the efforts aimed at stabilizing atmospheric $\mathrm{CO}_{2}$ levels. The absorption technique for $\mathrm{CO}_{2}$ in amines like Monoethanolamine (MEA), Diethanolamine (DEA) and Methyldiethanolamine (MDEA) have been commonly used in natural gas sweetening and is considered as the most important and mature post-combustion $\mathrm{CO} 2$ capture technology having been patented for natural gas sweetening since 1930 (Kohl and Nielsen, 1997). 
Although there has been development in the absorption technique and the availability of solvents for acid gas removal, there are certain issues that still need attention till date.

- Corrosion

- Solvent degradation

- Associated heat duty per $\mathrm{CO}_{2}$ loading

- Economy of the absorption/stripping column

Inline to address these problems associated with amine technology system, there is need to investigate more reliable alternative solvents or technologies having good physical and chemical properties with regards to high $\mathrm{CO}_{2}$ loading capacities, low vapor pressures, low to moderate viscosities, thermal and chemical stabilities and high kinetic rates of absorption..

Aminated polymers though in use for years but it has very few research literature, it were specially applied as solid sorbents based on amine-treated polymers to capture $\mathrm{CO}_{2}$ from closed environments, such as space shuttles and submarines, containing less than $1 \% \mathrm{CO}_{2}$ (Satyapal et al. 2001). A feed stream containing $\mathrm{CO}_{2}$ is pumped through a packed bed of solid sorbent; $\mathrm{CO}_{2}$ adsorbs on the sorbent by interaction with the amine functional groups. The sorbent is regenerated by temperature-swing adsorption or pressureswing adsorption or a combination of both processes. Thus, application of aqueous colloidal suspensions of monodispersed aminated poly(GMAs) for $\mathrm{CO}_{2}$ capture is a novel idea which this work investigates its viability.

\section{MATERIALS AND METHODS}

This research work involved two major parts, the polymer synthesis and its kinetics study. Firstly, two types of aminated polyglycidylmethacrylate particles, poly(GMA) were synthesized: non-porous aminated poly(GMA) particles, NPGMA and porous mono dispersed aminated poly(GMA) particles, PGMA.

Poly(GMA) particles with narrow size distribution of approximately $2.0 \mu \mathrm{m}$ were produced by standard dispersion polymerization method in ethanol/water media using glycidylmethacrylate (GMA) as monomer, 2,2'azobisisobutyronitrile (AIBN) as initiator, poly(vinyl pyrolidone (PVP) as a stabilizer, ethanol/water as dispersion medium and ammonia as co-initiator and functional group. The monomer, GMA supplied by Rohm and Haas Ltd, Germany was washed with $10 \%$ aqueous sodium hydroxide solution to remove inhibitor and stored in refrigerator until used. The initiator, AIBN was from BDH Chemicals Ltd, UK. The dispersion medium was prepared by mixing proper amounts of ethanol obtained from Merck A.G., Germany and distilled water. The steric stabilizer, PVP (K-30, MW: 40,000) was supplied by Fluka Chemika, Switzerland, ammonia from BDH Chemicals, Uk was also used in the recipe.

The dispersion polymerization process was applied to experimentally synthesize the two proposed polymer particles, poly(GMA) of average size $2 \mu \mathrm{m}$ in a glass sealed cylindrical reactor following standard protocol further details are described elsewhere (Unsal et al., 2004, Elmas et al., 2005, Yalcin et al., 2006). The epoxy group on the micro surface was reacted with ammonia and become covalently attached to the primary amine group on the micro surface. The details of basic materials used in the polymer synthesis are stated below.

TABLE 1. PHYSICAL PROPERTIES OF THE REACTANTS AND

SOLVENTS USED

\begin{tabular}{|c|c|c|c|}
\hline Chemical & $\begin{array}{l}\text { Chemical } \\
\text { structure }\end{array}$ & Purity & $\begin{array}{l}\text { Molar } \\
\text { mass }\end{array}$ \\
\hline Ammonia & $\mathrm{NH}_{3}$ & $25 \%$ & 17.03 \\
\hline $\begin{array}{l}\text { 2-amino-2-hyroxymethyl- } \\
\text { 1,3-propanediol, (AHPD) }\end{array}$ & $\mathrm{H}_{2} \mathrm{NC}\left(\mathrm{CH}_{2} \mathrm{OH}\right)_{3}$ & $\geq 99 \%$ & 121.14 \\
\hline $\begin{array}{l}\text { 2,2'-Azobis(2- } \\
\text { methylpropionitrile), AIBN }\end{array}$ & $\mathrm{C}_{8} \mathrm{H}_{12} \mathrm{~N}_{4}$ & $98 \%$ & 164.21 \\
\hline Copper (1) bromide & $\mathrm{CuBr}$ & $98 \%$ & 143.45 \\
\hline Carbon dioxide & $\mathrm{CO}_{2}$ & $99.99 \%$ & 44.01 \\
\hline Cyclohexane & $\begin{array}{l}\mathrm{CH}_{2}\left(\mathrm{CH}_{2} \mathrm{CH}_{2}\right)_{2} \mathrm{C} \\
\mathrm{H}_{2}\end{array}$ & $\geq 98 \%$ & 84.16 \\
\hline Dibutyl-phthalate & $\mathrm{C}_{6} \mathrm{H}_{4}\left(\mathrm{CO}_{2} \mathrm{C}_{4} \mathrm{H}_{9}\right)_{2}$ & $\geq 98 \%$ & 278.34 \\
\hline $\begin{array}{l}\text { Ethylene dimethacrylate } \\
\text { (EDM) }\end{array}$ & $\mathrm{C}_{10} \mathrm{H}_{14} \mathrm{O}_{4}$ & $98 \%$ & 198.22 \\
\hline Ethanol & $\mathrm{CH}_{3} \mathrm{CH}_{2} \mathrm{OH}$ & $99.5 \%$ & 46.07 \\
\hline $\begin{array}{l}\text { Glycidyl methacrylate } \\
\text { (GMA) }\end{array}$ & $\mathrm{C}_{7} \mathrm{H}_{10} \mathrm{O}_{3}$ & $97 \%$ & 142.15 \\
\hline Methanol & $\mathrm{CH}_{3} \mathrm{OH}$ & $99.8 \%$ & 32.04 \\
\hline $\begin{array}{l}\text { N-(2-hydroxyethyl) } \\
\text { piperazine, (NHEPZ) }\end{array}$ & $\mathrm{C}_{6} \mathrm{H}_{14} \mathrm{~N}_{2} \mathrm{O}$ & $98.5 \%$ & 130.19 \\
\hline $\begin{array}{l}\text { Polyvinyl pyrrolidone, } \\
\text { (PVP) }\end{array}$ & $\left(\mathrm{C}_{6} \mathrm{H}_{9} \mathrm{NO}\right)_{\mathrm{n}}$ & $\geq 99 \%$ & 40,000 \\
\hline Tetrahydrofuran (THF) & $\begin{array}{l}- \\
\mathrm{CH}_{2}\left(\mathrm{CH}_{2}\right)_{2} \mathrm{CH}_{2} \mathrm{O}\end{array}$ & $\geq 99 \%$ & 72.11 \\
\hline Water & $\mathrm{H}_{2} \mathrm{O}$ & $\begin{array}{l}\text { Deioni } \\
\text { zed }\end{array}$ & 18.02 \\
\hline
\end{tabular}

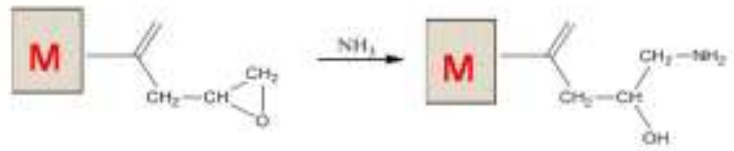

Figure 1. Basic structure of aminated polyglycidylmethacrylate particle

The colloidal suspensions of non-porous mono dispersed aminated polyglycidylmethacrylate particles, NPGMA and porous mono dispersed aminated polyglycidylmethacrylate particles, PGMA were respectively reacted with carbon dioxides solution at $298 \mathrm{~K}$ $\left(25^{\circ} \mathrm{C}\right)$ using the stopped flow technique to monitor and analyze the kinetics of the reactions.

The experimental set-up consisted of standard stoppedflow equipment (Hi-Tech Scientific, UK, Model SF61SX2). It is made up of four main units: a sample handling unit, a conductivity detection cell, A/D converter, and a micro-processor unit (Ali, 2005; Gordesli and Alper, 2011). Figure 2, shows picture of the equipment set up in the laboratory.

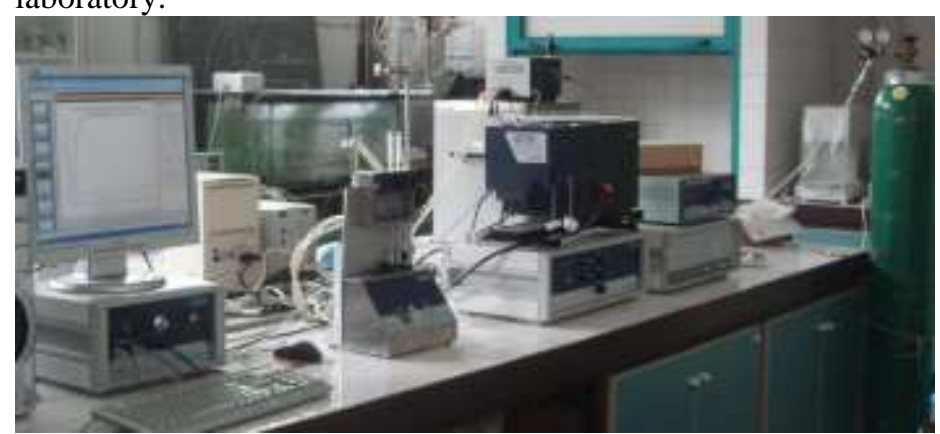

Figure 2. Stopped-flow equipment set up in the laboratory 
The sample handling unit is composed of stainless steel providing the support and enclosure of the sample flow circuit. The entire flow circuit, with the exception of the stop/waste syringe, is enclosed in a thermostat and maintained at a constant temperature by an external water bath within $\pm 0.1 \mathrm{~K}$. The front panel of the sample handling unit displays a temperature indicator with a resolution of 1 decimal unit. It also has an air pressure indicator and a single mixing mode indicator. A pneumatic air supply is used to control the movement of two drive plates located at the bottom of the internal syringes $\mathrm{A}$ and $\mathrm{B}$. During an experimental run, a fresh solution of $\mathrm{CO}_{2}$ is loaded into one syringe and a suspension solution of aminated poly(GMA) is loaded into the other. A "Kineticasyst" software is used to actuate the pneumatically controlled drive plate which pushes the solution accurately into the conductivity detection cell through a mixing loop. When running the sample measurement, these plates can control the stop/waste valve from the software, assisting the stop syringe and letting the valve automatically move to the waste position and empty the stop syringe. Then the valve moves back to the drive position, and the pneumatic drive plate pushes the fresh solution to the observation cell, and replaces the old solution from the previous run. In this unit, appropriate NPGMA/ PGMA solution and $\mathrm{CO}_{2}$ solution were placed in respective sealed drive syringes. For each experimental run, equal volumes of the solutions were suddenly pushed into and mixed in the stopped-flow mixer cell, the flow stopped for reaction to occur.

In the conductivity cell, the solution reacts to generate ions which conduct electricity through the platinum electrodes placed across the cell. The conductivity detection system directly measures the intrinsic rate of rapid homogeneous reaction. Changes in the concentration of the ions are measured in terms of changes in the potential across the cell and plotted against the time interval. A typical graph of voltage versus time is shown in Figure 3. Here, ion formation is monitored as function of time as the ion formation initiates a voltage change within the conductivity cell. The circuit measures the conductivity change and gives an output voltage directly proportional to the solution conductivity. The reaction software (kinetic studio) automatically calculates the observed pseudo-first-order rate constant $\left(\mathrm{k}_{\mathrm{o}}\right)$ based on least square regression and displaces the same at the micro-processor unit monitor. The other parts of the equipment are responsible for controlling the steeper motor, powering on/off all internal units and the sample handling unit, as well as controlling the automatically emptying waste cycle plus the air drive control circuitry.

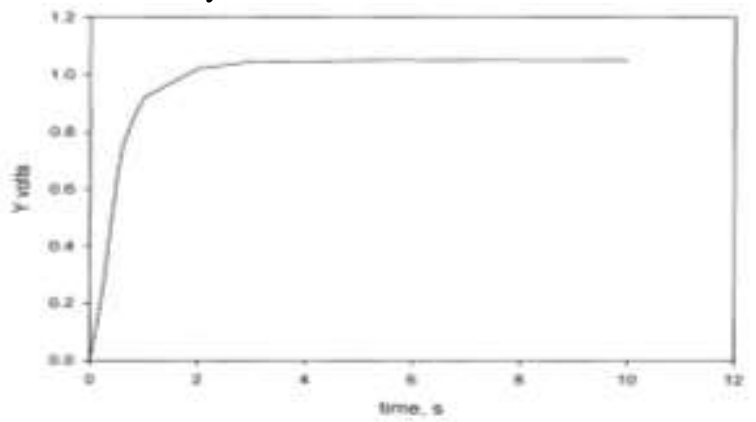

Figure 3. Typical nature of graph obtained by the stop flow technique
The graph of voltage versus time can be explained mathematically by an exponential equation resembling a first order kinetic equation.

$\mathrm{Y}=-\mathrm{A} \times \exp \left(-\mathrm{k}_{\mathrm{o}} \times \mathrm{t}\right)+\mathrm{Y}_{\infty}$

$\mathrm{C}_{\mathrm{A}}=\mathrm{C}_{\mathrm{AO}} \times \exp \left(-\mathrm{k}_{\mathrm{o}} \times \mathrm{t}\right)+\mathrm{l}$

Here $k_{o}$ is the pseudo first-order reaction rate constant as the experiment is carried out under a pseudo first-order condition, using an amine concentration at least 10 times larger than the $\mathrm{CO}_{2}$ concentration.

The stopped flow technique does not involve gas absorption so that the findings correspond to the intrinsic homogenous reaction rate of solutions (Alper, 1990). This direct method is not affected by the reversibility of the reaction and avoids the possible experimental errors caused by the depletion of the amine in the gas-liquid interface (Ali, 2005). In addition, each run only needs a small amount of reactants (approximately $0.1 \mathrm{ml}$ each), and the equipment is very easy to handle. In this work concentration of amine was always much in excess of that of $\mathrm{CO}_{2}$ usually the molar ratio was about 20:1 in order to satisfy the pseudo first order condition.

\section{RESULTS AND DISCUSSION}

The proposed suspension solutions containing amine group, NPGMA and PGMA were synthesized accordingly. Their reaction kinetics was investigated using the stopped flow method. The experimental data obtained were as presented below. Figure 4, shows a typical experimental run for $\mathrm{CO}_{2}$ - NPGMA system, other similar graphs were obtained for this system. Also Figure 5, shows a typical experimental run for $\mathrm{CO}_{2}$ - PGMA system.

Figure 4, shows typical combined average graph of experimental runs for $\mathrm{CO}_{2}-\mathrm{NPGMA}$ system at $298 \mathrm{~K}$. The result shows an obsereved rate constant, $\mathrm{k}_{\mathrm{o}}$ value of 4.02377 $\mathrm{s}^{-1}$

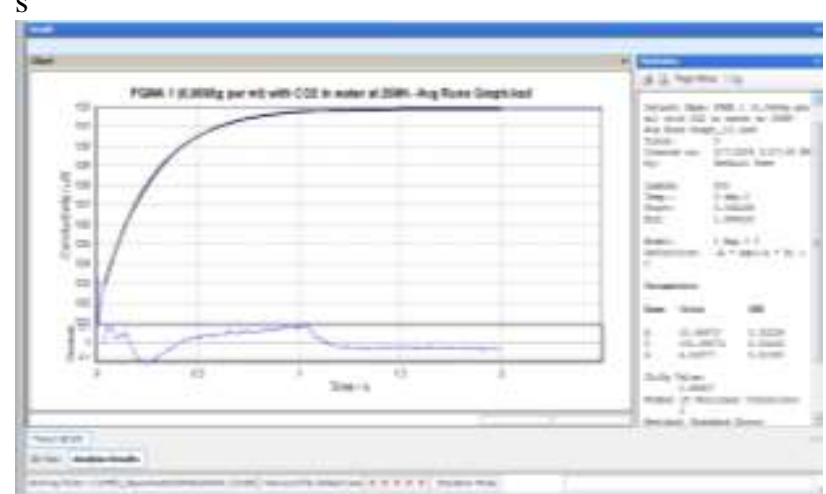

Figure 4. Combined avg. graph of experimental runs for $\mathrm{CO}_{2}-\mathrm{NPGMA}$ at $298 \mathrm{~K}$.

Figure 5, shows typical combined average graph of experimental runs for $\mathrm{CO}_{2}-\mathrm{PGMA}$ system at $298 \mathrm{~K}$. The result shows an observed rate constant, $\mathrm{k}_{\mathrm{o}}$ value of 18.37825 $\mathrm{s}^{-1}$ 


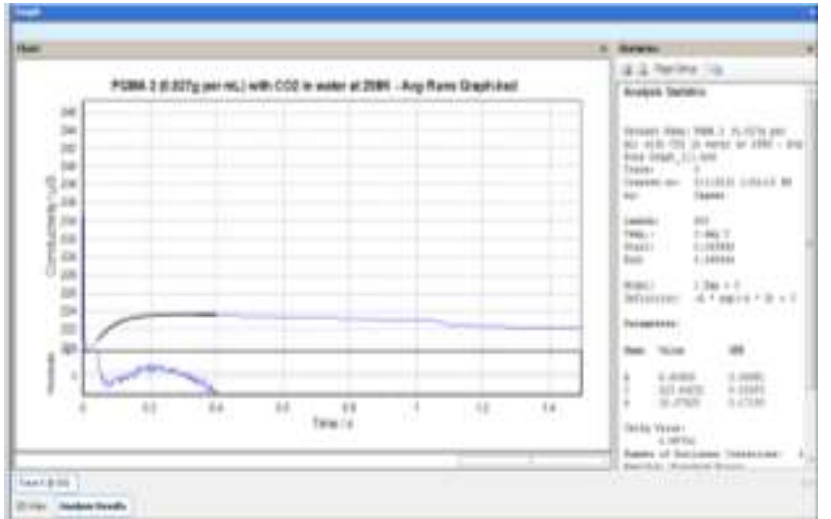

Fig. 5. Combined avg. graph of experimental runs for $\mathrm{CO}_{2}-$ PGMA at $298 \mathrm{~K}$

Based on the experimental results of reactions of the colloidal solutions of the NPGMA particles and PGMA particles with carbon dioxide respectively, the observed reaction rate constant of the two suspension solution are low in comparison to conventional amine like MEA. However, in view of the two particles under investigation it can be noted that the porous mono dispersed aminated polyglycidylmethacrylate particles, PGMA has an observed reaction rate constant, $\mathrm{k}_{\mathrm{o}}$ value of $18.37825 \mathrm{~s}^{-1}$ using sample of mass concentration of $0.027 \mathrm{~g} / \mathrm{ml}$. This indicates that the absorption rate of $\mathrm{CO}_{2}$ in the PGMA is over four times faster than its rate in NPGMA which gives $k_{0}$ value of $4.02377 \mathrm{~s}^{-1}$ using sample of mass concentration of $0.067 \mathrm{~g} / \mathrm{ml}$. This could be attributed to the porous nature of the particles, PGMA which enables the $\mathrm{CO}_{2}$ to penetrate the particles faster and it is being absorbed by the amine functional group attached to the porous particles.

\section{CONCLUSIONS}

The Non-porous mono dispersed aminated polyglycidylmethacrylate particles, NPGMA and Porous mono dispersed aminated polyglycidylmethacrylate particles, PGMA containing amine group were experimentally synthesized. The kinetics of reaction between carbon dioxide and suspension solutions of the synthesized polymer using stopped flow technique were investigated accordingly. All the experimental data for the various systems studied were modeled using the termolecular mechanism. The results gave very satisfactory pseudo-first-order plots.

In the amine functionalized particles of polyacrylates systems, it was found that all the particles synthesized exhibit carbon dioxide binding capabilities in aqueous colloidal solution though their values were below the currently used amine like MEA in flue gas system. However, the porous mono-dispersed aminated polyglycidylmethacrylate particles, PGMA which has observed reaction rate constant, $\mathrm{k}_{\mathrm{o}}$ of $18.37825 \mathrm{~s}^{-1}$ for $0.0270 \mathrm{~g} / \mathrm{ml}$ at $298 \mathrm{~K}$ posses as a promising colloidal solution that is applicable for $\mathrm{CO}_{2}$ capture. The system is less energy intensive and hence more economical because unlike aqueous amine solution process, the colloidal solution after absorbing $\mathrm{CO}_{2}$ can be filtered to remove the water content and only the aminated poly(GMA) beads containing the captured $\mathrm{CO}_{2}$ can be heated with a lower energy requirement to give up the $\mathrm{CO}_{2}$ while the beads is thus regenerated and recycled. Further comprehensive study for the amine functionalized particle is recommended.

\section{Acknowledgment}

The authors wish to acknowledge professional assistance in the polymer synthesis by Prof. Dr. Ali S. Tuncel of Chemical Engineering Department, Hacettepe University, Ankara, Turkey. Also the financial support of Turkish Scientific and Technological Research Council, TUBITAK through research grants (107M594) is gratefully acknowledged by the authors. The financial support from Federal University Ndufu Alike Ikwo, FUNAI, through TETFUND is also appreciated.

\section{REFERENCES}

[1]. E. Alper, "Kinetics of reactions of carbon dioxide with diglycolamine and morpholine", Chem. Eng. J. vol. 44(07), pp.14-21, 1990.

[2]. S. H. Ali, "Kinetic of the reaction of carbon dioxide with blends of amines in aqueous media using the stopped-flow technique", Int. J. Chem. Kinetics, vol. 37(7), pp. 391 - 405, September, 2004.

[3]. B. Elmas, M. Tuncel, G. Yalcin, S. Senel, A. Tuncel, "Synthesis of uniform, fluorescent poly(glycidyl methacrylate) based particles and their characterization by confocal laser scanning microscopy. Colloids and Surfaces A: Physicochem”, Eng. Aspects vol. 269, pp. 125 - 134, 2005.

[4]. F. P. Gordesli, and E. Alper, "The kinetics of carbon dioxide capture by solutions of piperazine and N-methyl piperazine", Int. J. of Global Warming vol. 3, pp. 67-76, 2001.

[5.] A. Henni, "Solubilities of gases in physical solvents and absorptoin rates of $\mathrm{CO}_{2}$ in a mixed solvent", Ph.D Dissertation, University of Regina, Saskatchewan, Canada, 2002.

[6]. S. Kadiwala, S. "Absorption rates of $\mathrm{CO}_{2}$ in aqueous and non-aqueous amine solutions and solubility of $\mathrm{CO}_{2}$ in aqueous piperazine solution" MSc. Thesis, University of Regina, Saskatchewan, Canada, 2008.

[7], A. Kohl, and R. Nielsen, Gas Purification, 5th ed., Gulf Publishing Company, Texas, 1997.

[8]. S. Satyapal, T. Filbum, J. Trela, J. Strange, "Performance and properties of a solid amine sorbent for carbon dioxide removal in space life support", Energy Fuels, vol. 15(2), pp. 250 - 255, 2001.

[9]. E. Unsal, S. T. Caml, T. Irmak, M. Tuncel, A. Tuncel, "Monodisperse poly(Styrene-co-Divinylbenzene) particles with relatively small pore size as HPLC packing material", Chromatographia, vol. 60 (9/10), pp. $252-260,2004$.

[10]. S. R. Weart, The Discovery of Global Warming (New Histories of Science, Technology, and Medicine), Harvard University Press, 2003.

[11]. G. Yalcın, B. Elmas, M. Tuncel, A. Tuncel, “A low, particle sized, Nonporous Support for Enzyme immobilization: uniform poly(glycidylmethacrylate) latex particles", J. of Applied Polymer Sci., vol. 101 , pp. $818-824,2006$. 